\title{
Caracterização de Isolados de Phytophthora infestans do Distrito Federal e de Goiás
}

\author{
Ailton Reis ${ }^{1}$, Fabiana H. S. Ribeiro ${ }^{2}$ \& Eduardo S. G. Mizubuti² \\ 'Embrapa Hortaliças, Cx. Postal 218, CEP 70359-970, Brasília, DF, e-mail ailton@cnph.embrapa.br; \\ ${ }^{2}$ Departamento de Fitopatologia, Universidade Federal de Viçosa, CEP 36570-000, Viçosa, MG
}

(Aceito para publicação em 18/07/2006)

Autor para correspondência: Ailton Reis

REIS, A., RIBEIRO, F.H.S. \& MIZUBUTI, E.S.G. Caracterização de isolados de Phytophthora infestans do Distrito Federal e de Goiás. Fitopatologia Brasileira 31:270-276. 2006.

\begin{abstract}
RESUMO
Foram caracterizados 123 isolados de Phytophthora infestans obtidos de 21 lavouras de tomateiro e oito de batateira, em municípios do Estado de Goiás e Cidades Satélites de Brasília, no período de abril de 2001 a setembro de 2003. Os isolados foram caracterizados para os marcadores grupo de compatibilidade (123 isolados); isoenzima glucose 6-fosfatoisomerase ( $\mathrm{Gpi}$ ) (34 isolados) e resistência aos fungicidas mefenoxam (77 isolados) e metalaxyl (32 isolados de batateira), usando o método de disco de folhas. Todos os 78 isolados de tomateiro foram classificados no grupo de compatibilidade A1, enquanto os 45 de batateira foram do grupo A2. Os fenótipos para Gpi dos isolados de tomateiro (19) e de batateira (15) foram 86/100, típico da linhagem clonal US-1, e 100/100, típico da linhagen clonal BR-1, respectivamente. Quanto à resistência a mefenoxam, constataram-se isolados de tomateiro resistentes (36\%), intermediários (48\%) e sensíveis (16\%). A maioria dos isolados de batateira foi classificada como sensível (82\%) e apenas 9\% de intermediários e resistentes. Dos isolados de batateira avaliados para resistência ao metalaxyl, $25 \%$ foram resistentes, $62 \%$ intermediários e $13 \%$ sensíveis. A população de $P$. infestans no Distrito Federal e no Estado de Goiás é constituída de duas linhagens clonais, com especificidade por hospedeiro.
\end{abstract}

Palavras-chave adicionais: requeima, tomateiro, batateira, variabilidade genética, resistência a fungicida.

\begin{abstract}
Characterization of Phytophthora infestans isolates from Distrito Federal and Goiás, Brazil

From April 2001 to September 2003, 123 isolates of Phytophthora infestans were collected in 21 tomato and eight potato fields of Distrito Federal (DF) and Goiás State (GO), Brazil. Isolates were characterized for mating type (123 isolates), glucose 6-phosphate-isomerase alloenzyme ( $G p i)$ (34 isolates), and for resistance to mefenoxam (77 isolates) and metalaxyl (32 potato isolates), using the leaf disc method. All the tomato isolates (78) were of the A1 mating type and all the potato isolates (45) were of the A2 mating type. Nineteen tomato and 15 potato isolates were tested for Gpi and were classified as 86/100 phenotype, typical of the US-1 clonal lineage, and 100/100 phenotype, typical of the BR-1 clonal lineage, respectively. Tomato isolates were $36 \%$ resistant to mefenoxam, $48 \%$ intermediate, and $16 \%$ sensitive. The majority of the potato isolates ( $82 \%$ ) were sensitive, $9 \%$ were intermediate, and $9 \%$ were resistant. Potato isolates tested for metalaxyl resistance were $25 \%$ resistant, $62 \%$ intermediate, and $13 \%$ sensitive. The population of $P$. infestans in the DF and GO is clonal, with two host-specific clonal lineages.
\end{abstract}

Additional keywords: late blight, tomato, potato, genetic variability, fungicide resistance.

\section{INTRODUÇÃO}

A região Centro Oeste é a principal produtora de tomate (Lycopersicon esculentum Mill.) para processamento industrial do Brasil. Somente o Estado de Goiás responde por cerca de $65 \%$ da produção nacional (Silva \& Giordano, 2000). Além disso, este Estado também é um importante produtor de tomate de mesa. No Distrito Federal, também se cultiva tomate de mesa principalmente para abastecer o mercado local. A produção de batata (Solanum tuberosum L.) na região Centro Oeste é menor que a das regiões Sul e Sudeste, mas os cultivos são comuns em cidades satélites de Brasília e nas regiões de Anápolis e Cristalina, em Goiás. Porém, nos últimos anos, tem-se verificado que produtores do Sul e do Sudeste têm ampliado seus cultivos em outras regiões do país, entre elas municípios de Goiás e do DF.

Como em outras regiões do país, a requeima ou mela, causada pelo oomiceto Phytophthora infestans (Mont.) de Bary, é uma das doenças mais importantes das duas culturas. Epidemias de requeima causam perdas significativas de produção e, por essa razão, os produtores dispendem expressiva parcela do custo de produção com seu controle. Não há variedades comerciais de batateira ou híbridos de tomateiro com altos níveis de resistência à requeima e o seu 
controle é feito quase exclusivamente com o uso de fungicidas (Mizubuti, 2001). Estes, além de causarem problemas aos produtores e consumidores, aumentam o custo de produção e o preço final do produto. Adicionalmente, o uso intensivo de fungicidas pode contribuir para a seleção de populações de $P$. infestans resistentes a alguns desses produtos, principalmente os mais específicos (Köller, 1998).

Do ponto de vista populacional, a seleção e a recombinação são mecanismos evolutivos que têm implicações para o manejo da requeima por interferirem na predominância de indivíduos resistentes a fungicidas. A pressão de seleção exercida por fungicidas específicos contribui para o estabelecimento de populações resistentes. Para $P$. infestans, este processo foi demonstrado ocorrer com o fungicida metalaxyl (Gisi \& Cohen, 1996). Os riscos de desenvolvimento de populações resistentes são maiores quando os indivíduos de uma população reproduzem-se sexuadamente, ou seja, em populações nas quais ocorre recombinação (Gisi et al., 2002). Portanto, faz-se necessário caracterizar populações para que se conheça seu potencial evolutivo (McDonald \& Linde, 2002).

Phytophthora infestans é organismo heterotálico e se reproduz sexuadamente quando há cruzamento entre isolados do grupo de compatibilidade A1 com A2 (Erwin \& Ribeiro, 1996; Goodwin, 1997). A ocorrência de isolados dos grupos A1 e A2 numa região sobre a mesma cultura aumenta as chances de reprodução sexuada e o surgimento de recombinantes, os quais podem apresentar características melhores de adaptabilidade, tais como maior agressividade e virulência, e resistência a fungicidas, o que dificulta o manejo da requeima (Goodwin, 1997). A ocorrência de reprodução sexuada em países da América do Norte e da Europa trouxe conseqüências como a geração e o estabelecimento de novos genótipos do patógeno, mais agressivos que os existentes, associados tanto a tomateiro como a batateira (Gavino et $a l ., 2000)$, além da participação de outro tipo de inóculo inicial, os oósporos, que possivelmente passaram a ter papel importante na epidemiologia da doença, contribuindo para um início mais antecipado da epidemia no campo (Turkensteen et al., 2000). Assim, o conhecimento do modo de reprodução de $P$. infestans contribui diretamente para o manejo da requeima e a determinação da ocorrência de isolados de diferentes grupos de compatibilidade deve ser o primeiro passo para esse estudo.

As recentes mudanças na população de $P$. infestans contribuíram para aumentar a chance de recombinação e, por conseguinte, aumentar a variabilidade genética do patógeno. Migrações de $P$. infestans do México, provável centro de origem do patógeno, trouxeram novos isolados tanto do grupo A1 como A2, para vários países da América do Norte, Europa, Ásia e América do Sul. Estes novos genótipos representam um problema a mais para o manejo da doença, pois a maioria é mais resistente ao metalaxyl que os genótipos até então presentes nestes países (Fry \& Goodwin, 1997). Em razão dessas mudanças, a caracterização de populações de $P$. infestans tornou-se parte integrante de estudos epidemiológicos e contribui para o embasamento de medidas de controle.

Para a caracterização de isolados de $P$. infestans, os marcadores mais utilizados são: grupo de compatibilidade, fenótipos para as isoenzimas glucose 6-fosfato-isomerase ( $\mathrm{Gpi}$ ) e peptidase (Pep), RFLP dos DNAs genômico (sonda RG-57) e mitocondrial (mtDNA), e resistência ao fungicida metalaxyl (Goodwin et al. 1994b). No Brasil, a estrutura clonal da população de $P$. infestans permite que se façam inferências confiáveis sobre as linhagens clonais utilizando apenas o grupo de compatibilidade e o perfil de Gpi (Reis et al., 2003).

Em estudos realizados em outras regiões do Brasil, foram constatados isolados dos dois grupos de compatibilidade (A1 e A2) de P. infestans. Entretanto, associados à cultura do tomateiro, só foram encontrados isolados do grupo A1, enquanto que os isolados de batateira, na sua maioria, eram do grupo A2 (Reis et al., 2003). Estes estudos foram realizados com isolados coletados nas regiões Sul e Sudeste, não havendo informações sobre a população do patógeno nas demais regiões do país. Por essa razão, este trabalho teve como objetivo a caracterização da população de $P$. infestans do Distrito Federal e Goiás, nos anos de 2001 a 2003.

\section{MATERIAL E MÉTODOS}

\section{Isolados de Phytophthora infestans}

No período de abril de 2001 a setembro de 2003, foram obtidos 123 isolados de P. infestans provenientes de folhas de tomateiro e batateira ou de frutos de tomate, coletados em lavouras comerciais ou experimentais, no Distrito Federal e no Estado de Goiás. As coletas foram realizadas em 29 campos, sendo oito de batateira e 21 de tomateiro. O número de isolados coletados por campo variou de 2 a 10 (Tabela 1). O isolamento do patógeno foi feito pelo método direto (Erwin \& Ribeiro, 1996) em meio B de centeio-sacarose-ágar (CSA) (Caten \& Jinks, 1968). Os isolados obtidos foram mantidos em tubos de ensaio com meio CSA, preservados em óleo mineral e armazenados em condições ambiente.

\section{Caracterização dos isolados}

Os isolados foram caracterizados quanto aos seguintes marcadores: grupo de compatibilidade, fenótipo para a isoenzima glucose-6-fosfato-isomerase ( $G p i)$, e resistência aos fungicidas mefenoxam (metalaxyl-m) e metalaxyl (Ridomil 2E).

\section{Grupo de Compatibilidade}

Os 123 isolados obtidos (78 de tomateiro e 45 de batateira) foram pareados com dois isolados-padrão, um do grupo A1 (pertencente à linhagem clonal US-1) e um do grupo A2 (linhagem clonal BR-1), coletados na região Sudeste do Brasil (Reis et al., 2003). Os pareamentos foram feitos em placas de Petri de $90 \mathrm{~mm}$ de diâmetro, contendo $20 \mathrm{~mL}$ de 
TABELA 1 - Isolados de Phytophthora infestans obtidos em municípios do Distrito Federal DF e do Estado de Goiás $\mathrm{GO}$, com os respectivos grupos de compatibilidade, fenótipo para a isoenzima glicose-6-fosfato-isomerase (Gpi) e provável linhagem clonal

\begin{tabular}{|c|c|c|c|c|c|c|c|}
\hline $\begin{array}{l}\text { Município- } \\
\text { Lavoura }\end{array}$ & $\begin{array}{l}\text { Unidade da } \\
\text { Federação }\end{array}$ & $\begin{array}{l}\text { Mês/Ano } \\
\text { da Coleta }\end{array}$ & Hospedeiro & $\begin{array}{l}\text { Número de } \\
\text { Isolados }\end{array}$ & $\begin{array}{c}\text { Grupo de } \\
\text { Compatibilidade }\end{array}$ & $\begin{array}{l}\text { Fenótipo } \\
\text { para Gpi* }\end{array}$ & $\begin{array}{c}\text { Linhagem } \\
\text { Clonal }\end{array}$ \\
\hline Gama-1 & $\mathrm{DF}$ & $04 / 2001$ & Tomateiro & 03 & A1 & $86 / 100$ & US-1 \\
\hline Gama-2 & & $05 / 2001$ & & 07 & & $86 / 100$ & \\
\hline $\begin{array}{l}\text { Vargem } \\
\text { Bonita-1 }\end{array}$ & & $11 / 2001$ & & 08 & & $86 / 100$ & \\
\hline Gama-6 & & $02 / 2002$ & & 10 & & $86 / 100$ & \\
\hline Gama-7 & & $04 / 2002$ & & 02 & & $86 / 100$ & \\
\hline Gama-8 & & $04 / 2002$ & & 03 & & $86 / 100$ & \\
\hline Gama-9 & & $04 / 2002$ & & 02 & & $86 / 100$ & \\
\hline Brazlândia -3 & & $04 / 2002$ & & 04 & & $86 / 100$ & \\
\hline Planaltina -1 & & $05 / 2001$ & & 05 & & $86 / 100$ & \\
\hline Planaltina -3 & & $05 / 2002$ & & 02 & & $86 / 100$ & \\
\hline Planaltina -4 & & $05 / 2002$ & & 03 & & $86 / 100$ & \\
\hline Planaltina -5 & & $07 / 2003$ & & 03 & & - & \\
\hline Gama-3 & & $05 / 2001$ & Batateira & 06 & $\mathrm{~A} 2$ & $100 / 100$ & BR-1 \\
\hline Gama-4 & & $06 / 2001$ & & 10 & & $100 / 100$ & \\
\hline Gama-5 & & $07 / 2001$ & & 05 & & $100 / 100$ & \\
\hline Brazlândia -1 & & $07 / 2001$ & & 03 & & $100 / 100$ & \\
\hline Brazlândia -2 & & $04 / 2002$ & & 07 & & $100 / 100$ & \\
\hline Planaltina -2 & & $07 / 2001$ & & 09 & & $100 / 100$ & \\
\hline Goianápolis -1 & GO & $06 / 2001$ & Tomateiro & 03 & A1 & $86 / 100$ & US-1 \\
\hline Abadiânia -1 & & $03 / 2002$ & & 06 & & $86 / 100$ & \\
\hline Goianápolis -2 & & $04 / 2003$ & & 02 & & - & \\
\hline Goianápolis -3 & & $05 / 2003$ & & 02 & & - & \\
\hline Morrinhos -1 & & $05 / 2003$ & & 02 & & - & \\
\hline Novo Gama -1 & & $07 / 2003$ & & 04 & & - & \\
\hline Orizona -1 & & $07 / 2003$ & & 03 & & - & \\
\hline Vianópolis -1 & & $07 / 2003$ & & 02 & & - & \\
\hline Vianópolis -2 & & $09 / 2003$ & & 02 & & - & \\
\hline Cristalina -1 & & $04 / 2002$ & Batateira & 03 & $\mathrm{~A} 2$ & $100 / 100$ & BR-1 \\
\hline Cristalina -2 & & $05 / 2002$ & & 02 & & $100 / 100$ & \\
\hline
\end{tabular}

meio V8-ágar (10\%) clarificado (Erwin \& Ribeiro, 1996). Um fragmento de meio de cultura, com aproximadamente $0,5 \mathrm{~cm}$ de largura $\mathrm{x} 3 \mathrm{~cm}$ de comprimento, contendo micélio com crescimento ativo de um isolado-padrão, foi retirado e depositado num dos extremos da placa. Outro fragmento $(0,5$ a $0,6 \mathrm{~cm} \times 5 \mathrm{~cm})$ de meio de cultura, foi retirado de colônias com 8 a 14 dias de cultivo, do isolado desconhecido, e depositado no outro extremo da placa, afastado em 3,5 a $4 \mathrm{~cm}$ do padrão. Dessa forma, para cada isolado desconhecido, foram confeccionadas duas placas, uma contendo o pareamento do isolado com um isolado A1 e outra com o isolado A2. As placas foram mantidas em incubadora BOD a $18{ }^{\circ} \mathrm{C}$ no escuro. Após duas semanas de incubação, as placas foram observadas sob microscópio estereoscópio para a presença de oósporos. Os isolados que apresentaram formação de oósporos com o padrão A1 foram classificados como A2 e os que o fizeram com o padrão A2, foram classificados como A1. As interações dúbias foram repetidas. Alguns dos isolados foram testados para a possibilidade de autocompatibilidade por meio do pareamento de dois fragmentos da mesma cultura.

\section{Isoenzima (Gpi)}

Analisou-se o fenótipo da isoenzima glucose 6 - fosfato - isomerase (Gpi) em uma amostra de 34 isolados, sendo 19 de tomateiro e 15 de batateira. Todos os 34 isolados avaliados foram coletados nos anos de 2001 ou 2002. Foi utilizada a eletroforese de enzimas em gel de acetato de celulose, conforme descrito por Goodwin et al. (1995). Os alelos que codificam para a enzima $G p i$ foram determinados por números (em percentagem) que representam a mobilidade das bandas no gel em relação a padrões previamente estabelecidos (Goodwin et al., 1995). Os isolados-padrão utilizados foram os mesmos do teste de grupo de compatibilidade.

Resistência aos fungicidas Mefenoxam e Metalaxyl 
A resistência ao fungicida mefenoxam de 77 isolados (33 de batateira e 44 de tomateiro) e ao fungicida metalaxyl (32 isolados de batateira) foi determinada com base na capacidade do patógeno esporular sobre discos de folha do hospedeiro (Matuszak et al., 1994; Sozzi \& Staub, 1987). Discos de $15 \mathrm{~mm}$ de diâmetro, foram retirados de folíolos de tomateiro 'IPA-5' ou de batateira 'Bintje', cultivados em casa-de-vegetação com 6 a 12 semanas de idade. Utilizaram-se folíolos de tomateiro para avaliar a resistência de isolados de tomateiro e folíolos de batateira para avaliar os isolados deste hospedeiro. Cinco discos de folhas foram postos para flutuar, com a face abaxial voltada para cima, em placas de Petri de 9,0 $\mathrm{cm}$ de diâmetro, contendo $20 \mathrm{~mL}$ de uma suspensão de 0,5 , ou $100 \mu \mathrm{g} / \mathrm{mL}$ de mefenoxam ou metalaxyl.

Cada disco foi inoculado com uma gota de $20 \mu \mathrm{L}$ de uma suspensão de $2 \times 10^{4}$ esporângios de $P$. infestans $/ \mathrm{mL}$. O inóculo foi preparado a partir de folíolos de tomateiro 'IPA5' (isolados de tomateiro) ou batateira 'Bintje' (isolados de batateira) apresentando esporulação abundante do patógeno. Após a inoculação, as placas foram transferidas para incubadoras, a $18{ }^{\circ} \mathrm{C}$ com fotoperíodo de $16 \mathrm{~h}$. A avaliação foi realizada após 6 dias de incubação, estimandose a esporulação do patógeno sobre os discos com auxílio de escala de notas (Sozzi et al., 1992) com seis classes: $0=$ sem sintomas aparentes, $1=$ necrose sem esporulação, $2=$ até $5 \%$ de esporulação, $3=5-20 \%, 4=20-50 \%$ e $5=$ mais de $50 \%$ da superfície do disco coberta por esporulação do patógeno. Cada isolado foi testado duas vezes. Para o caso de resultados divergentes, o teste foi conduzido uma terceira vez.

Para determinar a reação dos isolados ao fungicida, a porcentagem de esporulação nos discos de folha postos para flutuar em suspensão contendo 5 ou $100 \mu \mathrm{g} / \mathrm{mL}$ de mefenoxam foi dividida pela porcentagem de esporulação do mesmo isolado, na testemunha (sem fungicida) e multiplicados por 100. Isolados que apresentaram esporulação menor que $40 \%$ da observada no tratamento testemunha, foram considerados como sensíveis. Isolados que, a $5 \mu \mathrm{g} / \mathrm{mL}$, apresentaram esporulação superior a $40 \%$ da esporulação da testemunha, mas que, a $100 \mu \mathrm{g} / \mathrm{mL}$, apresentaram esporulação inferior a $40 \%$ em relação à testemunha, foram considerados intermediários. Foram considerados como resistentes, isolados com esporulação superior a 40\% da testemunha, em 5 e 100 $\mu \mathrm{g} / \mathrm{mL}$ de mefenoxam ou metalaxyl (Therrien et al., 1993).

\section{Análise de dados}

Empregou-se o teste de independência de Chiquadrado para testar se os grupos de isolados A1 e A2 diferem quanto às freqüências de isolados resistentes, intermediários e sensíveis a mefenoxam (Reis et al., 2005). As análises foram realizadas com o programa SAS System versão 8.0.

\section{RESULTADOS E DISCUSSÃO}

Todos os 78 isolados de tomateiro foram caracterizados como do grupo de compatibilidade sexual A1 e, aqueles avaliados para Gpi, apresentaram o fenótipo
86/100. Estas duas características são típicas da linhagem clonal US-1, identificada inicialmente nos Estados Unidos (Goodwin et al., 1994a, b) e que, até pouco tempo, apresentava ampla distribuição na maioria dos países onde a população do patógeno foi caracterizada (Goodwin et al., 1994b). Os 45 isolados de batateira foram caracterizados como grupo de compatibilidade A2 e, aqueles avaliados para a enzima Gpi, apresentaram o fenótipo 100/100 (Tabela 1), características típicas da linhagem clonal BR1, considerada nova e anteriormente encontrada em outras regiões do Brasil infectando batateira (Goodwin, 1994b; Reis et al., 2003). A alta uniformidade entre os isolados testados para os marcadores grupo de compatibilidade e Gpi já fora observada em trabalhos com isolados das regiões Sul e Sudeste do Brasil (Reis et al., 2003) e indica ausência de reprodução sexuada na população do patógeno.

A população de $P$. infestans do Distrito Federal e de Goiás tem estrutura clonal, uma vez que, não foram detectados isolados recombinantes quando se utilizou o perfil de Gpi como marcador. Em outros países, após a introdução de isolados do grupo A2 foi constatada a ocorrência de reprodução sexuada e formação de população recombinante (Drenth et al., 1994; Gavino et al., 2000; Goodwin et al., 1998; Sujkowski et al., 1994; Turkensteen, et al., 2000). A ocorrência de isolados do grupo A1 e do grupo A2 no Distrito Federal e em Goiás possibilita a infecção de uma mesma lavoura por isolados A1 e A2, uma vez que podem ser encontrados plantios comerciais de batateira e tomateiro próximos. Mesmo assim, não se detectou população recombinante. Esse fato pode ser explicado pela alta especificidade por hospedeiro, verificada nas populações de $P$. infestans nesta região e também outros países, e nas regiões Sul e Sudeste do Brasil (Suassuna et al., 2004). Diferenças de adaptabilidade em dado hospedeiro dificultam a ocorrência conjunta de isolados A1 e A2 em um campo de tomateiro ou batateira. Outra razão para a não detecção de recombinantes pode estar relacionada à infertilidade dos oósporos resultantes do cruzamento. Tal fato já fora observado por Mosa et al. (1993) no Japão. Adicionalmente, é possível que ocorra cruzamento entre isolados A1 e A2 em uma planta, haja produção de oósporos viáveis, mas a progênie resultante é menos adaptada que as duas linhagens clonais parentais. Assim, a progênie não se estabeleceria, conforme já observado por Mayton et al. (2000), nos Estados Unidos.

A alta especificidade por hospedeiro faz com que isolados A1 estejam associados a tomateiro, enquanto isolados A2 a batateira. Foi demonstrado que, isolados de $P$. infestans do Brasil que infectam tomateiro são mais adaptados a esse hospedeiro que isolados oriundos de batateira e vice versa (Suassuna et al., 2004). A ocorrência de isolados de dois grupos de compatibilidade causando epidemias em tomateiro ou batateira, numa intensidade que permitisse formação de oósporos em número suficiente, seria pouco provável devido à especificidade por hospedeiro das linhagens clonais de P. infestans encontradas na região. 
Ainda assim, não é possível eliminar de modo taxativo a não ocorrência de reprodução sexuada. É possível que esse processo esteja ocorrendo e não tenha sido detectado devido a problemas de amostragem ou inviabilidade dos oósporos. Além de não haver evidências fortes nos dados gerados com os marcadores, não há evidência biológica da ocorrência da reprodução sexuada por nunca se ter encontrado oósporos nos materiais vegetais analisados.

Ao contrário do que ocorreu em outros países, não houve desalojamento completo da linhagem clonal US-1 no Sul e Sudeste do Brasil e também no Distrito Federal e em Goiás. Entretanto, pode ter havido um desalojamento desta linhagem clonal da cultura da batateira por BR-1. Em tomateiro, esta linhagem continuou estabelecida por ser adaptada a este hospedeiro e por não haver outra linhagem clonal de maior agressividade. Em vários locais, com a introdução dos novos genótipos de $P$. infestans, houve desalojamento das populações existentes por isolados mais agressivos e, em muitos casos, resistentes ao metalaxyl (Day \& Shattock, 1997; Koh et al., 1994; Spielman et al., 1991). Acredita-se que a introdução de novos genótipos de P. infestans no Brasil tenha ocorrido por meio de batata semente. Portanto, é provável que os genótipos introduzidos sejam mais adaptadas à batateira que a tomateiro.

Houve grande variação dos isolados avaliados quanto à resistência ao fungicida mefenoxam. As freqüências nas classes de sensibilidade analisadas diferiram entre os isolados A1 e A2 $\left(\chi^{2}=27,8 ; P<0,00001\right)$. Para isolados de tomateiro, observou-se maior freqüência de isolados resistentes (36\%) ou intermediários (48\%) e menor de sensíveis (16\%) quando comparados com os isolados de batateira, para os quais estas freqüências foram de $9 \%, 9 \%$ e $82 \%$, respectivamente (Figura 1). Possivelmente, o uso mais intensivo desse fungicida em tomateiro, em relação a batateira, pode ter contribuído para essa diferença. No Distrito Federal e em Goiás, a cultura do tomateiro tem sido mais explorada que a da batateira, com cultivos em todos os períodos do ano. Tal fato possibilita a

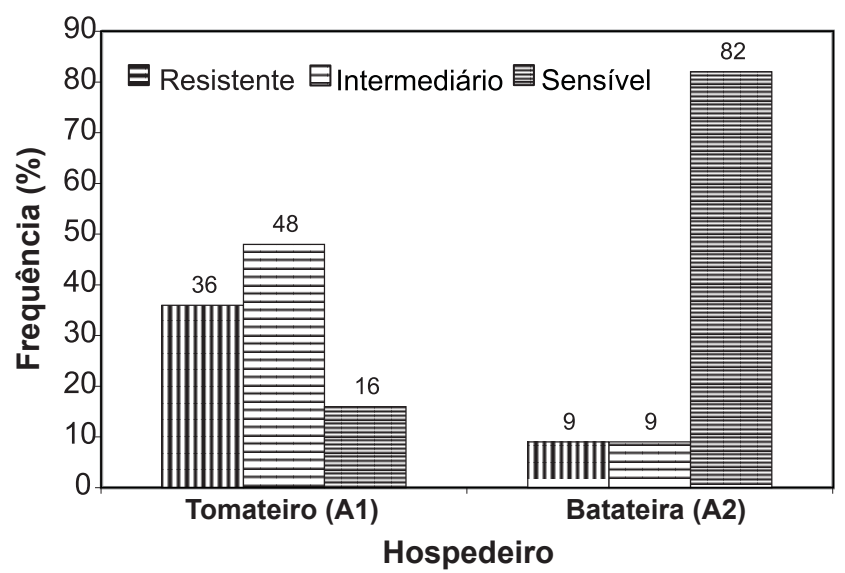

FIG. 1 - Sensibilidade ao fungicida mefenoxam dos isolados de Phytophthora infestans de tomateiro e batateira, coletados no Distrito Federal e em Goiás. presença constante de inóculo, que fica exposto à ação do fungicida, o que proporciona maior oportunidade para a seleção de indivíduos resistentes na população do patógeno. Ao contrário, a cultura da batateira tem sido explorada principalmente na época seca do ano, onde a requeima é menos problemática, havendo menor necessidade de uso do fungicida. Além disso, como há uma descontinuidade do plantio da cultura, reduz-se a quantidade de inóculo e há menor pressão de seleção sobre o patógeno.

Isolados de $P$. infestans insensíveis ao mefenoxam foram encontrados em quase todas as lavouras de tomateiro amostradas e apenas em algumas de batateira. Fato similar foi recentemente relatado para metalaxyl. Em outras regiões do Brasil, fora do Distrito Federal e Goiás, verificou-se que as duas populações do patógeno continham isolados resistentes, intermediários e sensíveis ao metalaxyl (Reis et al., 2005). Este fato também foi observado em Filipinas (Koh et al., 1994), África do Sul (McLeod et al., 2001) e Equador (Adler et al., 2004), países tropicais ou subtropicais onde a população do patógeno também é clonal.

Os isolados de batateira diferiram quanto à sensibilidade às duas formas de metalaxyl avaliadas, metalaxyl e metalaxyl-m (mefenoxam). Enquanto a maioria dos isolados foi resistente $(25 \%)$ ou intermediário $(62 \%)$ para o primeiro fungicida (Figura 2), mais de $80 \%$ foram sensível ao segundo. Apesar da maior eficiência do mefenoxam,

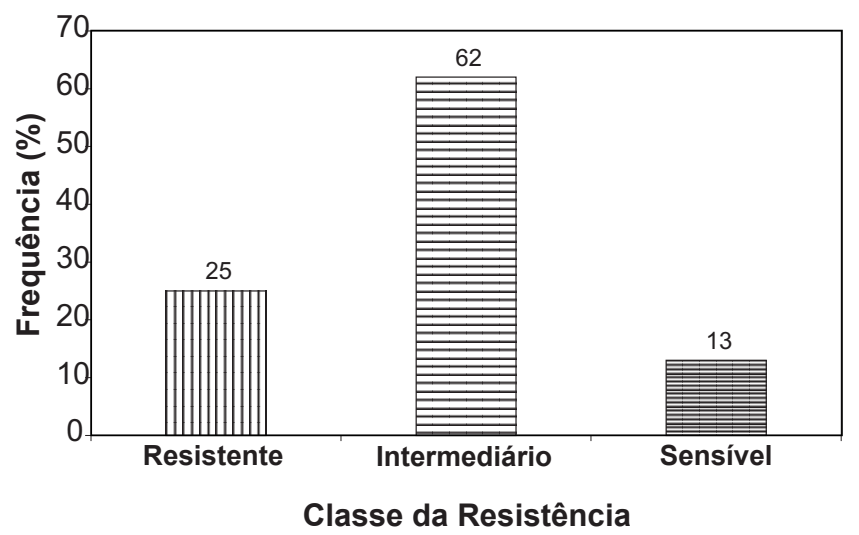

FIG. 2 - Sensibilidade ao fungicida metalaxyl (Ridomil 2E) de isolados de Phytophthora infestans de batateira, coletados no Distrito Federal e em Goiás.

isolados resistentes ao produto foram detectados no presente estudo. Há que se considerar também a preocupação quanto à resistência cruzada entre produtos do mesmo grupo. A situação ora favorável ao mefenoxam pode evoluir para um cenário de ineficácia do mesmo. Para evitar ou minimizar este problema, o produto deve ser utilizado de maneira preventiva e não curativa, conforme preconizado pelo fabricante e dentro de um sistema de rotação e mistura de produtos sistêmicos com protetores (Gisi \& Cohen, 1996).

Conclui-se que a população de $P$. infestans do Distrito Federal e de Goiás apresenta alta uniformidade para 
grupo de compatibilidade e fenótipo da enzima $G p i$, com provavelmente apenas uma linhagem clonal em tomateiro (US-1) e outra em batateira (BR-1). Porém, há grande variação quanto à resistência aos fungicidas mefenoxam e metalaxyl, com tendência a maior freqüência de isolados resistentes ao segundo fungicida.

\section{REFERÊNCIAS BIBLIOGRÁFICAS}

ADLER, N.E., ERSELIUS, L.J., CHACON, M.G., FLIER, W.G., ORDONEZ, M.E., KROON, L.P.N.M. \& FORBES, G.A. Genetic diversity of Phytophthora infestans sensu lato in Ecuador provides new insight into the origin of this important plant pathogen. Phytopathology 94:154-162. 2004.

CATEN, C.E. \& JINKS, J.L. Spontaneous variability of single isolates of Phytophthora infestans I. Cultural variation. Canadian Journal of Botany 46:329-348. 1968.

DAY, J.P. \& SHATTOCK, R.C. Aggressiveness and other factors relating to displacement of populations of Phytophthora infestans in England and Wales. European Journal of Plant Pathology 103: 379-391. 1997.

DRENTH, A., TAS, I.C.Q. \& GOVERS, F. DNA fingerprinting uncovers a new sexually reproducing population of Phytophthora infestans in the Netherlands; significance and consequences. European Journal of Plant Pathology 100:97-107. 1994.

ERWIN, D.C. \& RIBEIRO, O.K. Phytophthora Diseases Worldwide. Saint Paul, MN. APS Press. 1996.

FRY, W.E. \& GOODWIN, S.B. Re-emergence of potato and tomato late blight in the United States. Plant Disease 87:13491357. 1997.

GAVINO, P.D., SMART, C.D., SANDROCK, R.W., MILLER, J.S., HAMM, P.B., LEE, T.Y., DAVIS, R.M. \& FRY, W.E. Implications of sexual reproduction for Phytophthora infestans in the United States: Generation of an aggressive lineage. Plant Disease 84:731735. 2000.

GISI, U. \& COHEN, Y. Resistance to phenylamide fungicides: a case study with Phytophthora infestans involving mating type and race structure. Annual Review of Phytopathology 34:549-572. 1996.

GISI, U., SIEROTZKI, H., COOK, A. \& MCCAFFERY, A. Mechanisms influencing the evolution of resistance to Qo inhibitor fungicides. Pest Management Science 58: 859-867. 2002.

GOODWIN, S.B. The population genetics of Phytophthora. Phytopathology 87:462-473. 1997.

GOODWIN, S.B., COHEN, B.A., DEHAL, K.L. \& FRY, W.E. Migration from Northern Mexico as the probable cause of recent genetic changes in populations of Phytophthora infestans in the United States and Canada. Phytopathology 84:553-558. 1994a.

GOODWIN, S.B., COHEN, B.A. \& FRY, W.E. Panglobal distribution of a single clonal lineage of the Irish potato famine fungus. Proceedings of the National Academy of Science of the USA 91:11591-11595. 1994b.

GOODWIN, S.B., SCHNEIDER, R.E. \& FRY, W.E. Use of cellulose-acetate electrophoresis for rapid identification of allozyme genotypes of Phytophthora infestans. Plant Disease 79:1181-1185. 1995.
GOODWIN, S.B., SMART, C.D., SANDROCK, R.W., DEAHL, K.L., PUNJA, Z.K. \& FRY, W.E. Genetic change within populations of Phytophthora infestans in the United States and Canada During 1994 to 1996: role of migration and recombination. Phytopathology 88:939-949. 1998.

KOH, Y.J., GOODWIN, S.B., DYER, A.T., COHEN, B.A., OGOSHI, A., SATO, N. \& FRY, W.E. Migrations and displacements of Phytophthora infestans populations in East Asian countries. Phytopathology 84:922-927. 1994.

KÖLLER, W. Chemical approaches to managing plant pathogens. In: Ruberson, J.R. (Ed.) Handbook of pest management. New York NY. Marcel Dekker Inc. 1998. pp. 337-376.

McDONALD, B.A. \& LINDE, C. Pathogen population genetics, evolutionary potential, and durable resistance. Annual Review of Phytopathology 40:349-379. 2002.

McLEOD, A., DENMAN, S., SADIE, A. \& DENNER, F.D.N. Characterization of South African isolates of Phytophthora infestans. Plant Disease 85:287-291. 2001

MATUSZAK, J.M., FERNANDEZ-ELQUEZABAL, J., GU, W.K., VILLARREAL-GONZALEZ, M. \& FRY, W.E. Sensitivity of Phytophthora infestans populations to metalaxyl in Mexico: Distribution and dynamics. Plant Disease 78:911-916. 1994.

MAYTON, H., SMART, C.D., MORAVEC, B., MIZUBUTI, E.S.G., MULDOON, A.E. \& FRY, W.E. Oospore survival and pathogenicity of single oospore recombinant progeny from a cross involving US-17 and US-8 genotypes of Phytophthora infestans. Plant Disease 84:1190-1196. 2000.

MIZUBUTI, E.S.G. Requeima ou mela da batata e do tomate. In: Luz, E.D.N., Santos, A.F., Matsuoka, K. \& Bezerra, J.L. (Eds.) Doenças causadas por Phytophthora no Brasil. Campinas SP. Editora Rural. 2001. pp. 100-174.

MOSA, A.A., KOBAYASHI, K., OGOSHI, A., KATO, M., \& SATO, N. Isoenzyme polymorphism and segregation in isolates of Phytophthora infestans from Japan. Plant Pathology 42:26-34. 1993.

REIS, A., SMART, C.D., FRY, W.E., MAFFIA, L.A. \& MIZUBUTI, E.S.G.. Characterization of isolates of Phytophthora infestans from Southern and Southeastern regions of Brazil, from 1998 to 2001. Plant Disease 87:896-900. 2003.

REIS, A., RIBEIRO, F.H.S., MAFFIA, L.A. \& MIZUBUTI, E.S.G. Sensitivity of Brazilian isolates of Phytophthora infestans to commonly used fungicides in tomato and potato crops. Plant Disease 89:1279-1284. 2005.

SILVA, J.B.C. \& GIORDANO, L.B. Produção mundial e nacional. In: Silva, J.B.C. \& Giordano, L.B. (Orgs.) Tomate para processamento industrial. Brasília DF. Embrapa Hortaliças. 2000. p. 8-11.

SOZZI, D., SCHWINN, F.J. \& GISI, U. Determination of the sensitivity of Phytophthora infestans to phenylamides: a leaf disc method. Bulletin OEPP 22:306-309. 1992.

SOZZI, D. \& STAUB, T. Accuracy of methods to monitor sensitivity of Phytophthora infestans to phenylamide fungicides. Plant Disease 71:422-425. 1987.

SPIELMAN, L.J., DRENTH, A., DAVIDSE, L.C., SUJKOWSKI, L.J., GU, W.K., TOOLEY, P.W. \& FRY, W.E. A second world-wide migration and population displacement of Phytophthora infestans? Plant Pathology 40:422-430. 1991. 


\section{A. Reis et al.}

SUASSUNA, N.D., MAFFIA, L.A. \& MIZUBUTI, E.S.G. Aggressiveness and host specificity of Brazilian isolates of Phytophthora infestans. Plant Pathology 53:405-413. 2004.

SUJKOWSKI, L.S., GOODWIN, S.B., DYER, A.T. \& FRY, W.E. Increased genotypic diversity via migration and possible occurrence of sexual reproduction of Phytophthora infestans in Poland. Phytopathology 84:201-207. 1994.
THERRIEN, C.D., TOOLEY, P.W., SPIELMAN, L.J., FRY, W.E., RITCH, D.L. \& SHELLY, S.E. Nuclear DNA content, allozyme phenotypes and metalaxyl sensitivity of Phytophthora infestans from Japan. Mycological Reserach 97:945-950. 1993.

TURKENSTEEN, L.J., FLIER, W.G., WANNINGEN, R. \& MULDER, A. Production, survival and infectivity of oospores of Phytophthora infestans. Plant Pathology 49:688-696. 2000. 